\title{
Endometriosis is an important cause of pelvic pain in adolescence
}

\author{
Marina de Paula Andres ${ }^{1 *}$, Sergio Podgaec ${ }^{2}$, Karina Belickas Carreiro ${ }^{3}$, Edmund Chada Baracat ${ }^{4}$ \\ ${ }^{1}$ Collaborating Physician at Hospital das Clínicas, Faculty of Medicine, University of São Paulo (HC-FMUSP), Brazil \\ ${ }^{2}$ Post-doctoral Professor at the Division of Gynecology at the Faculty of Medicine, University of São Paulo, Head of the endometriosis clinic at HC-FMUSP, Brazil \\ ${ }^{3}$ Resident Physician at the Gynecology Division at HC-FMUSP, Brazil \\ ${ }^{4}$ Full Professor of Gynecology, FMUSP, Brazil
}

Study conducted at the Hospital das Clínicas, Faculty of Medicine, University of São Paulo (FMUSP), São Paulo, SP

Article received: $7 / 2 / 2014$ Accepted for publication: $7 / 23 / 2014$

*Correspondence: Address: Av. Dr. Enéas de Carvalho Aguiar, 255, Cerqueira César São Paulo - SP marina.dpandres@gmail.com

http://dx.doi.org/10.1590/1806-9282.60.06.015

Conflict of interest: none

\section{SUMMARY}

Objective: despite endometriosis being a common disease, where early detection is key to preventing its progression, it is a condition often overlooked in adolescents. The aim of this study was to report the clinical characteristics of adolescent patients with endometriosis monitored in a tertiary hospital.

Methods: a retrospective study of 394 patients undergoing surgery with a histological diagnosis of endometriosis at the Endometriosis Division of the Gynecology Department at the Hospital das Clínicas of the University of São Paulo Medical School from 2008 to 2013. 21 adolescents were included (aged under 21 years).

Results: the age ranged from $17.95 \pm 1.48$ years, the average time for diagnostic confirmation was $2.96 \pm 2.93$ years, and the age at the onset of symptoms was $15.28 \pm 3.03$ years on average. The sites affected were ovarian $(38 \%)$, peritoneal (47.6\%) and retrocervical (23.8\%). Dysmenorrhea was found in $80.9 \%$ of adolescents (severe in $33.3 \%$ of cases) and chronic pelvic pain in $66.6 \%$.

Conclusion: endometriosis in adolescents is an important differential diagnosis from pelvic pain and ovarian cysts, mainly among those with no response to conventional treatment. The main forms of involvement are peritoneal and ovarian. Despite the onset of symptoms in adolescence and advances in imaging methods, the diagnosis of this disease is still delayed.

Keywords: endometriosis, adolescent, dysmenorrhea, ovarian cysts.

\section{INTRODUCTION}

Endometriosis is a gynecological disease defined by the presence of glands and/or endometrial stroma outside the uterine cavity. ${ }^{1}$ The sites of disease involvement are the ovaries and retrocervical region, most often beyond the pelvic peritoneum, vagina, rectum, sigmoid, appendix, ureter and bladder, among others. ${ }^{2}$ One of the most common gynecological diseases, it may be present in 10$15 \%$ of women of childbearing age and up to $70 \%$ of women with a diagnosis of chronic pelvic pain. ${ }^{1,3}$ Its etiopathogenesis is still controversial and several theories have been proposed to justify the presence of the disease. ${ }^{1,4,5}$ It can be classified as superficial, ovarian and deep, the latter being characterized by the infiltration of endometrial implants above a depth. ${ }^{6,7}$

Endometriosis presents diverse clinical presentations. The main complaint of patients with endometriosis is chronic pelvic pain (non-cyclical) and dysmenorrhea, with an incidence of up to $75 \%$. Other complaints include in- fertility, deep dyspareunia and cyclic urinary and intestinal disorders associated with the menstrual period. ${ }^{5}$ The prevalence of endometriosis can reach $40-60 \%$ in patients complaining of dysmenorrhea and $30-40 \%$ in women complaining of infertility. ${ }^{6,8-11}$

This clinical condition can affect women during the reproductive period, including adolescence, defined as transition from childhood to adulthood, occurring between 10 to 19 years according to the World Health Organization (WHO). ${ }^{12}$ The main gynecological complaint by adolescents is dysmenorrhea, which affects between 60 and $93 \%$ of these patients. In most cases, this is primary or functional dysmenorrhea related to more frequent ovulatory cycles after 2 to 3 years of menarche. The pathophysiology of primary dysmenorrhea is still controversial and involves the release of leukotrienes and prostaglandins which cause systemic symptoms such as nausea and headache, and local pelvic symptoms, secon- 
dary to potent vasoconstriction and myometrial contraction, leading to ischemia and pain. ${ }^{13}$ Despite the high prevalence of dysmenorrhea in adolescents, many girls do not seek professional help or treatment. ${ }^{14}$ In a 2006 study, Houston et al. ${ }^{15}$ reported that $98 \%$ of teens use non-pharmacological therapies such as rest and warm compresses (with success rates of $40 \%$ or less) and $30-70 \%$ self-treatment with simple analgesics, with $57 \%$ using doses below those recommended. ${ }^{15}$

Secondary dysmenorrhea is that related to pelvic abnormalities and can be found in up to $10 \%$ of adolescents with endometriosis as the primary cause. ${ }^{13}$ As the incidence of gynecological diseases increases with age, secondary dysmenorrhea is more prevalent in young adults than adolescents. ${ }^{13}$

The treatment of endometriosis in adolescents presents particularities owing to the age of the patients. The use of hormonal contraceptives and anti-inflammatory drugs does not have any restriction, however, the use of $\mathrm{GnRH}$ analogues should be analyzed because of its side effects. ${ }^{16}$

\section{Objective}

Although endometriosis is a common disease, where early detection is key to preventing its progression, it is a condition often overlooked in patients during puberty. The aim of this study was to report the clinical characteristics of adolescent patients with endometriosis monitored in a tertiary hospital.

\section{Methods}

The study was conducted retrospectively by surveying medical records, thereby exempt from the approval of the Research Ethics Committee.

A retrospective analysis of the database belonging to the Endometriosis Sector at the Gynecology Clinic Division at the University of São Paulo Medical School's Hospital das Clínicas, (HC-USP) was conducted in the period from 2008 to 2013. The inclusion criterion was patients up to 20 years of age with a histologically confirmed diagnosis of endometriosis.

After anamnesis and clinical examination, all patients with clinically suspected endometriosis underwent a specialized image evaluation for this purpose, with transvaginal ultrasound and pelvic examination with bowel preparation prior to the exam or magnetic resonance imaging of the pelvis (if the patient had not started sexual activity). Clinical data related to the different pains reported by patients are measured by a visual analog scale, ranging from zero to 10 , where 10 is the worst pain.

Clinical hormonal treatment with combined contraceptives or continuous progestogens is indicated for patients who do not present evidence of lesions in this assessment (as it may be superficial endometriosis), or in cases of ovarian endometriomas less than $3 \mathrm{~cm}$ or when there is deep endometriosis, provided this does not affect the ureter, appendix, terminal ileum and or rectosigmoid in conditions of sub-occlusion. Periodically, at average intervals of 6 months, patients are clinically reassessed and undergo imaging exams, where appropriate. Medication treatment failure is considered if there is no improvement in symptoms (measured with the aid of the visual pain scale) and/or an increase in lesions, even during the course of steroid hormone use. When there are no lesions visualized in the imaging exam, then diagnostic laparoscopy is recommended and, in the case of deep endometriosis and/or ovarian endometrioma surgical treatment of the diseases is recommended.

Using this protocol, from the 394 patients undergoing surgery with a diagnosis of endometriosis in this period, 21 adolescents were selected from this group. In addition to the data above, all patients were assessed for symptoms, age at diagnosis, duration of clinical history, level of education, site of onset of the disease, and family history. They were also assessed in relation to the presence of outbreaks of disease in the peritoneum, ovaries and/ or deep infiltrative locations.

\section{RESULTS}

The mean age of patients was $17.95 \pm 1.48$ years, ranging from 13-20 years. The race of patients was predominantly white $(n=15)$, corresponding to $68 \%$ of cases. The level of education was high in affected patients, corresponding to $72.7 \%(n=16)$ with a high school diploma or still studying at this level. Only two patients presented a family history of endometriosis (Figure 1).

The average time elapsed between onset of symptoms and the diagnostic confirmation was $2.96 \pm 2.93$ years, ranging from six months to four years, and the age of onset of symptoms was $15.28 \pm 3.03$ years on average (Table 1 ). The sites affected by the disease are described in Table 2. 


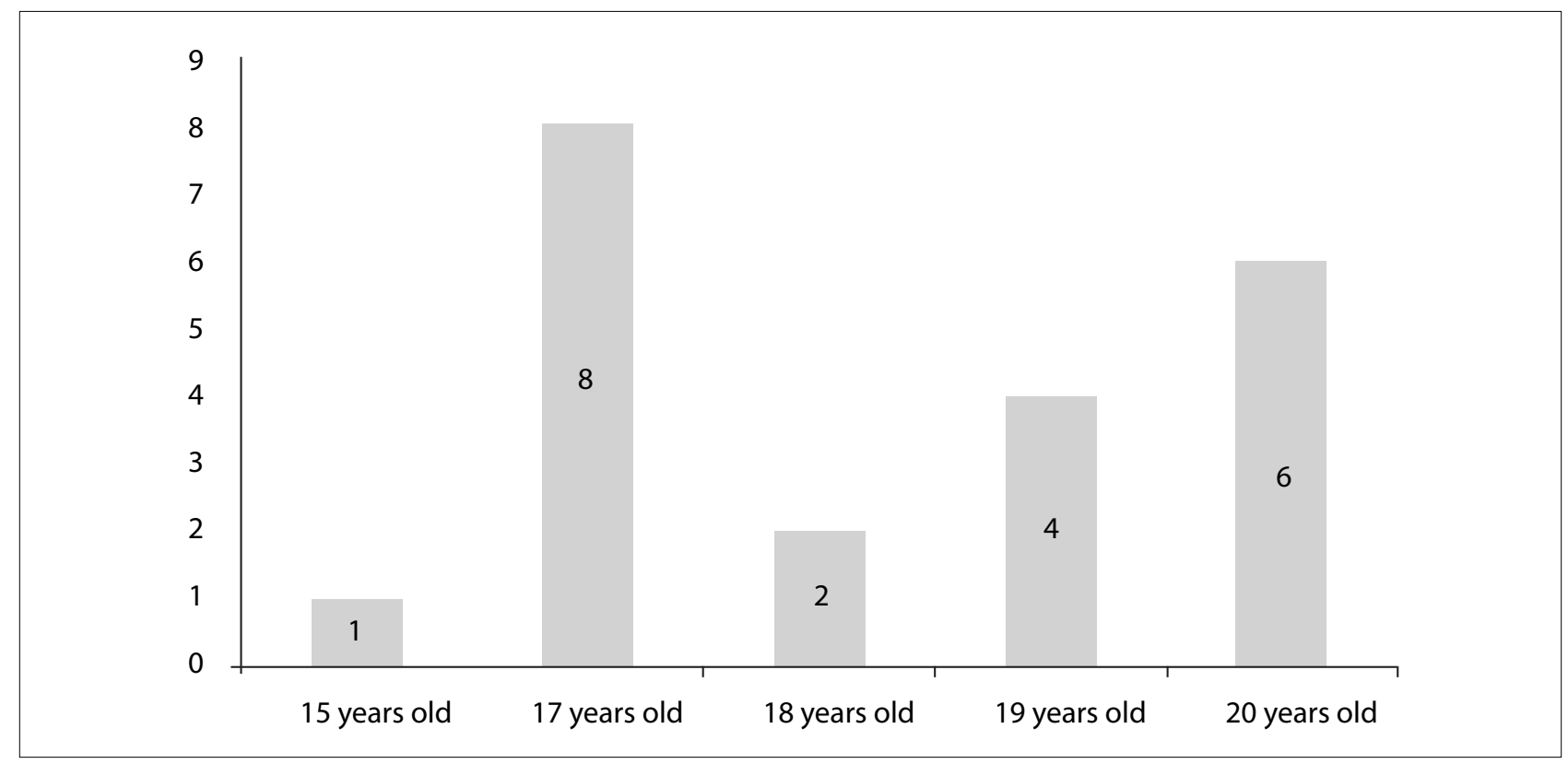

FIGURE 1 Number of adolescents with endometriosis by age. Hospital das Clínicas. 2008-2013.

TABLE 1 Clinical condition of adolescents with

\section{endometriosis}

\begin{tabular}{l|l} 
Symptoms & \% (n) \\
\hline Dysmenorrhea & $80.9(17)$ \\
\hline Light (VAS 1 to 4) & $28.5(6)$ \\
\hline Moderate (VAS 5 to 7) & $19(4)$ \\
\hline Incapacitating (VAS 8 to 10) & $33.3(7)$ \\
\hline Chronic pelvic pain & $66.6(14)$ \\
\hline Infertility & $4.7(1)$ \\
\hline Deep dyspareunia & $33.3(7)$ \\
\hline Cyclic bowel symptoms & $14.2(3)$ \\
\hline VAS: visual analogue scale for pain (zero to 10). &
\end{tabular}

TABLE 2 Clinical characteristics of adolescents with endometriosis

\begin{tabular}{l|l} 
Clinical characteristics & $\%(\mathbf{n})$ \\
\hline Family history of endometriosis & $9.4(2)$ \\
\hline Race & \\
\hline White & $71.4(15)$ \\
\hline Black & $23.8(5)$ \\
\hline Mixed & $7(1)$ \\
\hline Site affected by the disease & \\
\hline Ovaries & $38(8)$ \\
\hline Superficial peritoneal & $47.6(10)$ \\
\hline Retrocervical & $23.8(5)$ \\
\hline Retrocervical and ovaries & $9.4(2)$ \\
\hline
\end{tabular}

After surgery, 19 patients received adjuvant clinical treatment: combined oral contraceptives $(42.8 \%), \mathrm{GnRH}$ analogue $(33.3 \%)$, oral progestogen (19\%), levonorgestrel-releasing intrauterine system (4.7\%) and Danazol (4.7\%).

\section{Discussion}

It is estimated that the prevalence of endometriosis in adolescents is $45-70 \%$ in those undergoing laparoscopy for chronic pelvic pain. ${ }^{13,16}$ In the present study, among adolescent patients with a confirmed endometriosis diagnosis, the mean age was $18.24 \pm 1.48$ years, ranging from $13-20$ years. The median age is 17 years, in accordance with other studies in the literature where the average age of diagnosis was 18.6 years. ${ }^{16}$

As presented in other studies, the incidence of endometriosis is higher in white patients. In this study, the incidence was $68 \%$ of patients. Templeman reported a higher incidence of school absenteeism among white patients with endometriosis than in black patients, which may represent a higher proportion of disease in this group of adolescents. ${ }^{17}$ The importance of endometriosis in patients with a higher educational level was also noted in this study, as $72.7 \%$ of patients had been attending high school, which has also been observed by other authors. ${ }^{17-19}$

We noted that the average time elapsed between onset of symptoms of pain and the diagnostic confirmation was $2.96 \pm 2.93$ years, varying from six months to four years, and the age of onset of symptoms was 15.28 
\pm 3.03 years on average. Part of these complaints reported by the adolescents should be considered as relating to common psychosocial disorders during this period of life, which ultimately cause delays in the diagnosis of chronic diseases. According to the American Association of Endometriosis, $66 \%$ of adult women describe the onset of complaints of pelvic pain before reaching 20 years of age, and even those that seek help from specialists need at least four professionals to reach the correct diagnosis. Patients with symptoms of endometriosis before 19 years of age took an average of 12.1 years for the diagnosis of endometriosis, while women over 30 took 3.3 years. ${ }^{2,8,13,20}$

Arruda et al. ${ }^{21}$ applied questionnaires to 200 patients, on average, 26 months after histological diagnosis of endometriosis. Among the patients analyzed, $2.5 \%$ were aged less than 20 years, $50 \%$ were between 30 and 39 years, and $20.5 \%$ were older than 40 years. The main complaint was dysmenorrhea, present in $67 \%$ of patients, and chronic pelvic pain was found in $12.5 \%$, infertility in $10 \%$, dyspareunia in $5.5 \%$, and more than one symptom in $88 \%$. The mean interval between onset of symptoms and diagnosis of endometriosis was seven years, taking nine years when the symptoms began in adolescence, and only three years when started after 30 years of age. Patients with complaints of pelvic pain took on average six months to see a doctor, while patients complaining of infertility took on average 1.7 years. Although $44 \%$ of patients develop symptoms before 20 years of age, only $3.5 \%$ received a definitive diagnosis in this age group. ${ }^{21}$

Another study published in 2010 was based on data from 12 centers in Italy, which study patients with endometriosis. 39 patients aged between 10 and 21 years were evaluated, regarding complaints presented and laparoscopic findings with histological confirmation. The average age at diagnosis was 18.6 years, with three cases diagnosed before 15 years of age. Genital malformations that could justify the precocity of the diseases were not observed. The main complaint triggering the start of the investigation was chronic pelvic pain with non-cyclic presentation or acute pelvic pain. In three patients, the investigation was based on adnexal masses. ${ }^{16}$

A study conducted in New Zealand assessed 163 patients with histological diagnosis of endometriosis in the period from 2003 to 2009. 20 of these patients were adolescents. Among adolescent patients, the main complaint was dysmenorrhea in $80 \%$ versus $55 \%$ among adults, and the use of more than one analgesic for pain control was $95 \%$ versus $59 \%$, respectively. ${ }^{22}$
In over half the cases evaluated in our study, the adolescents had moderate or disabling intensity dysmenorrhea (VAS over 5), with 16 of them being part of their initial complaint. Chronic pelvic pain was also noted in the majority of patients (66.6\%). This data is corroborated by the literature, in which the symptom leading to diagnosis of the disease was chronic or acute pelvic pain in $79 \%$ of patients, and pelvic mass in $21 \% .{ }^{14-16,17,23}$

The majority of disease involvement was peritoneal (47.6\%) and ovarian (38\%). Deep endometriosis was diagnosed in $33.3 \%$ of adolescents, with retrocervical involvement in all of them, with no correlation with an exuberant clinical picture. The main symptom presented by this group was non-cyclic pelvic pain. In the literature, the early stages are less frequent in adolescents and ovarian endometriosis is common, suggesting that despite pain being the main symptom leading to gynecological examination, surgery is most appropriate when there are ultrasound findings of ovarian cysts. ${ }^{16,24}$

Postoperative treatment was mostly with combined oral contraceptives (42.8\%). The levonorgestrel-releasing intrauterine system was only used in one patient and the GnRH analogue was used in $33.3 \%$ of them. It should be highlighted that GnRH should not be used in patients younger than 17 years and its use should be for short periods due to the effects of hypoestrogenism, mainly hot flushes and osteopenia. ${ }^{16}$

\section{Conclusion}

Endometriosis in adolescents is a disease to be considered as an important differential diagnosis in pelvic pain and adnexal cysts, especially among those with pain resistant to the use of commonly used medication. The main forms of involvement are peritoneal and ovarian, and despite advances in imaging methods, there is still a delay in diagnosis of this disease, which often has symptoms starting in adolescence, bringing physical and emotional damage, with a major impact on quality of life in such girls. The gynecologist should be aware of the signs and symptoms to make an early diagnosis, thereby preventing progression of the disease and providing the most appropriate treatment for each patient.

\section{Resumo}

Endometriose é causa importante de dor pélvica na adolescência.

Objetivo: embora a endometriose seja uma doença prevalente, cujo diagnóstico precoce é fundamental para a 
prevenção de sua progressão, é uma condição frequentemente negligenciada em adolescentes. $\mathrm{O}$ objetivo deste estudo é levantar as características clínicas das pacientes adolescentes com endometriose acompanhadas em um hospital terciário.

Métodos: levantamento retrospectivo de 394 pacientes submetidas à cirurgia com diagnóstico histológico de endometriose no Setor de Endometriose da Divisão de Clínica de Ginecologia do Hospital das Clínicas da Faculdade de Medicina da Universidade de São Paulo, de 2008 a 2013. Foram incluídas 21 adolescentes (idade menor de 21 anos).

Resultados: a idade média foi de 17,95 $\pm 1,48$ anos, a média de tempo para a confirmação diagnóstica foi de 2,96 $\pm 2,93$ anos e a idade do início dos sintomas foi em média de $15,28 \pm 3,03$ anos. Os locais de acometimento foram ovariano $(38 \%)$, peritoneal $(47,6 \%)$ e retrocervical $(23,8 \%)$. Dismenorreia esteve presente em $80,9 \%$ das adolescentes (sendo severa em $33,3 \%$ dos casos) e dor pélvica crônica em $66,6 \%$.

Conclusão: endometriose em adolescentes é um importante diagnóstico diferencial de dor pélvica e cistos anexiais, principalmente entre aquelas sem resposta ao tratamento convencional. As principais formas de acometimento são peritoneais e ovarianas. Apesar do início dos sintomas na adolescência e dos avanços nos métodos de imagem, ainda se observa demora no diagnóstico dessa doença.

Palavras-chave: endometriose; adolescente; dismenorreia; cistos ovarianos.

\section{References}

1. Signorile PG, Baldi A. Endometriosis: new concepts in the pathogenesis. Int J Biochem Cell Biol. 2010;42(6):778-80.

2. Harel Z. Dysmenorrhea in adolescents. Ann N Y Acad Sci. 2008;1135:18595. Review.

3. Practice committee of American Society for Reproductive Medicine. Treatment of pelvic pain associated with endometriosis. Fertil Steril. 2008;90(5):s260-9. Review.
4. Podgaec S, Rizzo LV, Fernandes LF, Baracat EC, Abrao MS. CD4( ) CD25(high) Foxp3( ) cells increased in the peritoneal fluid of patients with endometriosis. Am J Reprod Immunol. 2012;68(4):301-8.

5. Bulun SE. Endometriosis. N Engl J Med. 2009;360(3):268-79. Review.

6. Hails G, Machsner S, Ebert AD. The diagnosis and treatment of deep infiltrating endometriosis. Dtsch Arztebl Int. 2010;107(25):446-56;quiz 456

7. Nisolle M, Donnez J. Peritoneal endometriosis, ovarian endometriosis, and adenomyotic nodules of the rectovaginal septum are three different entities. Fertil Steril. 1997;68(4):585-96.

8. Farquhar CM. Extracts from the "clinical evidence". Endometriosis. BMJ 2000;320(7247):1449-52. Review.

9. Bellelis PK, Dias JÁ Jr, Podgaec S, Gonzales M, Baracat EC, Abrão MS. Aspectos epidemiológicos e clínicos da endometriose pélvica - uma série de casos. Rev Assoc Med Bras. 2010;56(4):467-71.

10. Abrão MS, Gonçalves MO, Dias JA Jr, Podgaec S, Chamie LP, Blasbalg R Comparison between clinical examination, transvaginal sonography and magnetic resonance imaging for the diagnosis of deep endometriosis. Hum Reprod. 2007;22(12):3092-97.

11. Gonçalves MO, Podgaec S, Dias JA Jr, Gonzalez M, Abrão MS. Transvagina ultrasonography with bowel preparation is able to predict the number of lesions and rectosigmoid layers affected in cases of deep endometriosis, defining surgical strategy. Hum Reprod. 2010;25(3):665-71.

12. Rossi P, Ribeiro RM, Baracat EC. Manual de ginecologia de consultório. São Paulo: Atheneu; 2007. p.115-9.

13. Parker MA, Sneddon AE, Arbon P. The menstrual disorder of teenagers (MDOT) study: determining typical menstrual patterns and menstrua disturbance in a large population based study of Australian teenagers BJOG.2009;117(2):185-92.

14. Campbell MA, McGrath PJ. Non-pharmacologic strategies used by adolescents for the management of menstrual discomfort. Clin J Pain. 1999;15(4):313-20.

15. Houston AM, Abraham A, Huang Z, D'Angelo LJ. Knowledge, attitudes, and consequences of menstrual health in urban adolescent females. J Pediatr Adolesc Gynecol. 2006;19(4):271-5.

16. Vicino M, Parazzini F, Cipriani S, Frontino G. Endometriosis in young women the experience of GISE. J Pediatr Adolesc Gynecol. 2010;23(4):223-5.

17. Templeman C. Adolescent endometriosis. Obst Gynecol Clin North Am. 2009;36(1):177-85

18. Treloar SA, Bell TA, Nagle CN, Purdie DM, Green AC. Early menstrua characteristics associated with subsequent diagnosis of endometriosis. Am J Obstet Gynecol. 2010;202(6):534.e1-6.

19. Chapron C, Lafay-Pillet MC, Monceau E, Borghese B, Ngô C, Souza C, et al Questioning patients about their adolescent history can identify markers associated with deep infiltrating endometriosis. Fertil Steril. 2011;95(3):877-81.

20. Dmowski WP, Gebel HN, Braun DP. The role of cell-mediated immunity in pathogenesis of endometriosis. Acta Obstet Gynecol Scand. 1994;159(1):7-14

21. Arruda MS, Petta CA, Abrão MS, Benetti-Pinto CL. Time elapsed from onset of symptoms to diagnosis of endometriosis in a cohort study of Brazilian women. Hum Reprod.2003;18(4):756-9.

22. Roman JD. Adolescent endometriosis in the waikato region of New Zealand-a comparative cohort study with a mean follow-up time of 2.6 years. Aust N Z J Obstet Gynecol. 2010;50(2):179-83.

23. Bai SW, Cho HJ, Kim JY, Jeong KA, Kim SK, Cho DJ, et al. Endometriosis in an adolescent population: the severance hospital in Korean experience. Yonsei Med J. 2002;43(1):48-52.

24. Wright KN, Laufer MR. Endometrioma in adolescents. Fertil Steril. 2010;94(4):1529.e7-9 